\title{
Effects of Hand-Washing Facilities with Water and Soap on Diarrhea Incidence among Children under Five Years in Lao People's Democratic Republic: A Cross-Sectional Study
}

\author{
Yuko Noguchi ${ }^{1}$, Daisuke Nonaka ${ }^{1, * \mathbb{D}}$, Sengchanh Kounnavong ${ }^{2}$ and Jun Kobayashi ${ }^{1}$ \\ 1 Graduate School of Health Sciences, University of the Ryukyus, 207 Uehara, Nishihara-cho, Nakagami-gun, \\ Okinawa 903-0125, Japan; marubastusankakushikaku@yahoo.co.jp (Y.N.); junkobalao@gmail.com (J.K.) \\ 2 Lao Tropical and Public Health Institute, Ministry of Health, Samsenthai Road, Ban Kaognot, Sisattanack \\ District, Vientiane 01030, Laos; sengchanhkounnavong@hotmail.com \\ * Correspondence: nonakad@med.u-ryukyu.ac.jp; Tel.: +81-98-895-1666
}

check for

updates

Citation: Noguchi, Y.; Nonaka, D.; Kounnavong, S.; Kobayashi, J. Effects of Hand-Washing Facilities with Water and Soap on Diarrhea Incidence among Children under Five Years in Lao People's Democratic Republic: A Cross-Sectional Study. Int. J. Environ. Res. Public Health 2021, 18, 687. https://doi.org/10.3390/ ijerph18020687

Received: 17 November 2020 Accepted: 11 January 2021 Published: 14 January 2021

Publisher's Note: MDPI stays neutral with regard to jurisdictional clai$\mathrm{ms}$ in published maps and institutional affiliations.

Copyright: (C) 2021 by the authors. Licensee MDPI, Basel, Switzerland. This article is an open access article distributed under the terms and conditions of the Creative Commons Attribution (CC BY) license (https:// creativecommons.org/licenses/by/ $4.0 /)$.

\begin{abstract}
Diarrhea is a leading cause of death among children under five (U5) in Lao People's Democratic Republic (PDR). This study assessed the association between the presence of household hand-washing facilities with water and soap and diarrhea episodes among children U5 in Lao PDR. Data from the Lao Social Indicator Survey II were used. The outcome variable was diarrhea episodes in the two weeks preceding the survey. The main predictor variable was the presence of household hand-washing facilities with or without water and/or soap. Mixed-effect logistic regression analysis was used to assess the association, controlling for clustering, and other predictor variables. Of the 8640 households surveyed with 11,404 children, $49.1 \%$ possessed hand-washing facilities with both water and soap and $34.7 \%$ possessed hand-washing facilities with water alone. Children whose households possessed hand-washing facilities with water alone were significantly more likely to have a diarrhea episode compared to children whose households possessed hand-washing facilities with both water and soap (8.1\% vs. $5.9 \%$; odds ratio, 1.49 ; 95\% confidence interval, $1.22-1.81$ ). The association remained significant even after adjusting for other predictors. The absence of soap in hand-washing facilities was associated with higher odds of having a diarrhea episode among children U5 in Lao PDR.
\end{abstract}

Keywords: children; hand-washing; soap; diarrhea; household; Laos

\section{Introduction}

Diarrhea is a leading cause of death among children under five years of age (U5), especially in low- and lower middle-income countries [1,2]. According to the World Health Organization, approximately 525,000 children U5 die from diarrheal disease each year [3]. Lao People's Democratic Republic (PDR) is a lower middle-income country located in Southeast Asia. In Lao PDR, the mortality rate of children U5 remains high compared to those in neighboring countries such as Thailand, Vietnam, and Cambodia, which is due partly to diarrhea [4-6]. The Global Burden of Diseases Diarrhoeal Diseases Collaborators estimated that the mortality of diarrheal disease in children U5 was 97.1/100,000, and approximately 1,000,000 episodes occurred in children U5 in Lao PDR in 2015 [7].

Hand-washing in everyday life is effective for reducing the risk of diarrhea. A systematic review examined the impact of hand-washing with soap on the risk of diarrheal disease and reported that hand-washing with soap in community settings can reduce the risk of diarrheal disease by $42-47 \%$; therefore, interventions to promote hand-washing can save millions of lives a year [8]. According to another systematic review that assessed the effects of hand-washing promotion interventions on childhood diarrhea, community-based hand-washing promotion in low- and middle-income countries can reduce the incidence of diarrhea in children by approximately a quarter [9]. 
Rapid observations are widely used as a proxy measure of hand-washing practice, assuming that household members practice hand-washing with soap if a specific place for hand-washing is observed in a household with available water and soap [10]. In a nationwide survey, such as the Multiple Indicator Cluster Survey and the Demographic and Health Survey, rapid observations are widely adopted, since it can be challenging to measure hand-washing practice by direct observation because of the enormous associated costs and times. The Lao Social Indicator Survey II (LSIS II), a household-based nationwide survey that was implemented by the Lao government in 2017, also used rapid observations.

In Lao PDR, expanding the coverage of water, sanitation, and hygiene (WASH) facilities has been prioritized especially in rural areas and many WASH projects including open defecation free projects have been implemented [11]. However, very few projects measured project's impact on health outcomes including diarrhea. A comprehensive WASH in school project, which included water supply, sanitation, hand-washing, and behavior change interventions, was implemented in 492 primary schools across 13 provinces between 2013 and 2017 [12]. A cluster randomized controlled trial study was done in Saravan province to measure the project's impact on pupil absence, diarrhea, respiratory infection, and soiltransmitted helminth infection. The study found, however, that even among schools with the high level of fidelity and adherence, impact of the intervention was minimal. Thus, the study concluded that WASH in school alone may not achieve significant health gains without concurrent community and household WASH improvements including the improvement of hand-washing [13].

The association between hand-washing facilities with soap and diarrhea incidence among children U5 remains poorly understood in Lao PDR. To the best of our knowledge, two studies have assessed this association in Lao PDR. A cross-sectional study with 297 households in 50 villages in Saravan province examined associations between the presence of household hand-washing facilities and the infection status of diarrhea-causing pathogens among household members, including children U5 [14]. The study found that the presence of household hand-washing facilities was associated with lower infection rates of viral enteric pathogens and soil-transmitted helminths among household members. Another longitudinal study assessed diarrheal risk factors with 234 households from two villages in Saravan province, including all household members [15]. The study found that the presence of hand-washing with soap near or in the toilet was not associated with self-reported diarrhea episodes. The LSIS II included both rapid observation of the handwashing facilities with soap and diarrhea episodes in children U5 [4]. However, no analysis has been made on the association.

Therefore, the present study aimed to assess the association between the presence of household hand-washing facilities with water and soap and diarrhea episodes among children U5 in Lao PDR using data from the LSIS II. We have long conducted research concerning community health in rural Lao PDR. The present study was conducted as a part of a larger study that aims to inform strategies to promote hand-washing with soap in rural Lao PDR.

\section{Materials and Methods}

\subsection{Source of Data and Sample}

The present study used data from the LSIS II that were obtained from UNICEF (https://mics.unicef.org/surveys). Out of 11,812 children U5 eligible for the LSIS II, data were available for 11,720 children whose primary caretakers responded to the survey. From the 11,720 children, the present study excluded 316 children because of missing values or "don't know" responses to question items that were relevant to the present study. Overall, the present study included 11,404 children U5 with 9038 primary caretakers in 8640 households (spreadsheet S1: Dataset). 


\subsection{Outcome Variable}

The outcome variable was the presence of diarrhea illness episodes in children U5 in the two weeks preceding the survey. The outcome was measured by asking the following question to primary caretakers: "In the last two weeks, has (child name) had diarrhea?"

\subsection{Main Predictor Variable}

The predictor variable of interest was the presence of hand-washing facilities with water and soap. This variable had four categories: (1) hand-washing facilities with both water and soap, (2) hand-washing facilities with water alone, (3) hand-washing facilities without water and with/without soap, and (4) no hand-washing facilities. The variable was developed on the basis of three original variables of the LSIS II: "hand-washing facility," "water availability," and "soap availability." "Hand-washing facility" was measured by the following question item: "Can you please show me where members of your household most often wash their hands?" "Water availability" was measured by the following observation item: observe the presence of water at the place for hand-washing. "Soap availability" was measured by the following observation item: is soap, detergent, or ash/mud/sand present at the place for hand-washing?

\subsection{Other Predictor Variables}

Based on the LSIS II report and similar studies that examined the factors associated with childhood diarrhea, the present study included the 12 predictor variables below, which were categorized into four levels: the individual, caretaker, household, and village levels [16-20].

The individual-level variables included the sex and age of the child U5 and the supervision by primary caretaker (adequate/inadequate). The caretaker-level variables included the age and educational attainment of the primary caretaker (no formal education, early childhood education/primary/lower secondary, or above). The household-level variables included the number of household members (six or fewer/over six), sanitation facilities (improved/unimproved/no facilities), source of drinking water (improved/unimproved), ownership of domestic animals (yes/no), and household wealth (quartiles). To assess household wealth, an asset-based index was originally built using principal component analysis [21]. The main predictor variable was also included in the household-level variables. The village-level variables included living area (urban/rural) and source water quality determined by the level of Escherichia coli (E. coli) contamination in the three household-based samples per village ( $<11$ colony-forming units (CFUs) in all three samples $/ \geq 11$ CFUs in one or two samples $/ \geq 11$ CFUs in all three samples). Table A1 (Appendix A) presents detailed explanations of these predictor variables.

\subsection{Statistical Analysis}

Bivariate analyses were conducted to assess the association between the outcome variable and each of the predictor variables using Fisher's exact test or the chi-square test. Multivariate analyses were conducted using mixed-effect logistic regression. In the multivariate analyses, multi-level modeling was used to account for the hierarchical structure of the data: individuals (level 1) were nested within caretakers (level 2), caretakers were nested within households (level 3), and households were nested within villages (level 4). In the multivariate analyses, three models were examined: in Model 1, only the predictor of interest was included. In Model 2, the predictor of interest and the household-level variables were included. In Model 3, all of the predictor variables were included. The likelihood ratio test was used to assess the fitness of these models. The significance level was set at $p<0.05$ for all tests. The presence of multicollinearity was assessed using variance inflation factor (VIF) and a VIF > 5 was considered to indicate multicollinearity. These analyses were performed using Stata 14.2 (Stata Corp LP, College Station, TX, USA). 


\section{Results}

\subsection{Characteristics of the Study Participants}

Of the 11,404 children U5, $803(7.0 \%)$ children had experienced a diarrhea episode in the two weeks preceding the survey (Table 1$)$. Approximately half $(n=5805,50.9 \%)$ of the children U5 were male. The number of children in each age group did not differ greatly, ranging from $2187(19.2 \%)$ in 1 year to $2413(21.2 \%)$ in 3 years. The majority ( $n=9990$, $87.6 \%$ ) of the children U5 were supervised adequately by their primary caretaker.

Table 1. Characteristics of the study participants $(n=11,404)$.

\begin{tabular}{ccc}
\hline Characteristics & $n$ & $\%$ \\
\hline Diarrhea episode & & \\
No & 10,601 & 93.0 \\
Yes & 803 & 7.0 \\
\hline Sex of child & & \\
Male & 5805 & 50.9 \\
Female & 5599 & 49.1 \\
\hline Age of child & & \\
0 year & 2247 & 19.7 \\
1 year & 2187 & 19.2 \\
2 years & 2317 & 20.3 \\
3 years & 2413 & 21.2 \\
4 years & 2240 & 19.6 \\
\hline Adequate & & 87.6 \\
Inadequate & 9990 & 12.4 \\
\hline
\end{tabular}

\subsection{Characteristics of the Study Participants' Households}

The median age of the primary caretakers (interquartile range) was 28 years (range $=23-33)$. Of the 9038 primary caretakers, $7148(79.1 \%)$ had completed at least primary education (Table 2). The median number of household members (interquartile range) was six (range $=5-7$ ). Among the 8640 households with at least one child U5, hand-washing facilities were observed in 7815 (90.5\%) households, water was available in the hand-washing facilities of 7235 (83.7\%) households, and soap was available in the hand-washing facilities of $4279(49.5 \%)$ households. Nearly half of the households ( $n=4241$, $49.1 \%$ ) possessed hand-washing facilities with both water and soap available, whereas 2994 (34.7\%) households possessed hand-washing facilities with water alone. Meanwhile, $580(6.7 \%)$ households possessed hand-washing facilities without water and with/without soap, and $825(9.5 \%)$ households did not possess any hand-washing facilities. The majority ( $n=6062,70.2 \%$ ) of the households possessed improved sanitation facilities, while 2350 (27.2\%) households did not have any sanitation facilities. Most households had an improved source of drinking water $(n=7106,82.2 \%)$ and owned domestic animals $(n=7122$, $82.4 \%)$. The number of households in each household wealth quintile was almost the same across quintiles, ranging from 2141 (24.8\%) in the fourth group (richest group) to 2176 $(25.2 \%)$ in the third group (second richest group). 
Table 2. Characteristics of the study participants' households $(n=8640)$.

\begin{tabular}{|c|c|c|}
\hline Characteristics & $n$ & $\%$ \\
\hline \multicolumn{3}{|l|}{ Age of primary caretaker $(n=9038)$} \\
\hline$<20$ years & 653 & 7.2 \\
\hline 20-29 years & 4632 & 51.3 \\
\hline 30-39 years & 2792 & 30.9 \\
\hline$\geq 40$ years & 961 & 10.6 \\
\hline \multicolumn{3}{|l|}{ Educational attainment of primary caretaker $(n=9038)$} \\
\hline No formal education/early childhood education & 1890 & 20.9 \\
\hline Primary & 3543 & 39.2 \\
\hline Lower secondary or above & 3605 & 39.9 \\
\hline \multicolumn{3}{|l|}{ Number of household members } \\
\hline$\leq 6$ people & 5959 & 69.0 \\
\hline$>6$ people & 2681 & 31.0 \\
\hline \multicolumn{3}{|l|}{ Hand-washing facilities } \\
\hline Yes & 7815 & 90.5 \\
\hline No & 825 & 9.5 \\
\hline \multicolumn{3}{|l|}{ Water availability } \\
\hline Yes & 7235 & 83.7 \\
\hline No & 1405 & 16.3 \\
\hline \multicolumn{3}{|l|}{ Soap availability } \\
\hline Yes & 4279 & 49.5 \\
\hline No & 4361 & 50.5 \\
\hline \multicolumn{3}{|l|}{ Hand-washing facilities with water and soap ${ }^{1}$} \\
\hline Facility $(+)$, water $(+)$, soap $(+)$ & 4241 & 49.1 \\
\hline Facility $(+)$, water $(+)$, soap $(-)$ & 2994 & 34.7 \\
\hline Facility $(+)$, water $(-)$, soap $(+/-)$ & 580 & 6.7 \\
\hline Facility $(-)$, water $(-)$, soap $(-)$ & 825 & 9.5 \\
\hline \multicolumn{3}{|l|}{ Sanitation facilities } \\
\hline Improved sanitation facilities & 6062 & 70.2 \\
\hline Unimproved sanitation facilities & 228 & 2.6 \\
\hline No facilities & 2350 & 27.2 \\
\hline \multicolumn{3}{|l|}{ Source of drinking water } \\
\hline Improved & 7106 & 82.2 \\
\hline Unimproved & 1534 & 17.8 \\
\hline \multicolumn{3}{|l|}{ Ownership of domestic animals } \\
\hline Yes & 7122 & 82.4 \\
\hline No & 1518 & 17.6 \\
\hline \multicolumn{3}{|l|}{ Household wealth } \\
\hline First (poorest) & 2166 & 25.1 \\
\hline Second & 2157 & 25.0 \\
\hline Third & 2176 & 25.2 \\
\hline Fourth (richest) & 2141 & 24.8 \\
\hline
\end{tabular}

${ }^{1}(+)$ indicates presence, whereas (-) indicates absence.

\subsection{Characteristics of the Study Participants' Villages}

Of the 1159 villages included in the LSIS II, 792 (68.3\%) were rural villages (Table 3). In terms of E. coli contamination, the quality of source water was considered to be safe in 159 villages $(13.7 \%)$, whereas it was considered to be unsafe in 419 villages $(36.2 \%)$. 
Table 3. Characteristics of the study participants' villages $(n=1159)$.

\begin{tabular}{ccc}
\hline Characteristics & $n$ & \% \\
\hline Area & & \\
Urban & 367 & 31.7 \\
Rural & 792 & 68.3 \\
\hline Source water quality & & \\
$<11$ CFUs in all three samples & 159 & 13.7 \\
$\geq 11$ CFUs in one or two samples & 581 & 50.1 \\
$\geq 11$ CFUs in all three samples & 419 & 36.2 \\
\hline
\end{tabular}

CFUs, colony-forming units.

\subsection{Bivariate Analyses}

The factors significantly associated with diarrhea episodes among children U5 were the sex of the child, the age of the child, the supervision by the primary caretaker, the age of the primary caretaker, the educational attainment of the primary caretaker, the number of household members, soap availability, hand-washing facilities with water and soap, sanitation facilities, source of drinking water, and household wealth (Table 4). No significant differences were found for the rest of the variables.

Table 4. Bivariate analyses of the factors associated with diarrhea episodes $(n=11,404)$.

\begin{tabular}{|c|c|c|c|c|c|}
\hline \multirow{2}{*}{ Characteristics } & \multicolumn{2}{|c|}{ No Diarrhea Episode } & \multicolumn{2}{|c|}{ Diarrhea Episode } & \multirow{2}{*}{$p$-Value ${ }^{1}$} \\
\hline & $n$ & $\%$ & $n$ & $\%$ & \\
\hline \multicolumn{6}{|l|}{ Sex of child } \\
\hline Male & 5364 & 92.4 & 441 & 7.6 & 0.019 \\
\hline Female & 5237 & 93.5 & 362 & 6.5 & \\
\hline \multicolumn{6}{|l|}{ Age of child ${ }^{2}$} \\
\hline 0 year & 2039 & 90.7 & 208 & 9.3 & $<0.001$ \\
\hline 1 year & 1964 & 89.8 & 223 & 10.2 & \\
\hline 2 years & 2162 & 93.3 & 155 & 6.7 & \\
\hline 3 years & 2299 & 95.3 & 114 & 4.7 & \\
\hline 4 years & 2137 & 95.4 & 103 & 4.6 & \\
\hline \multicolumn{6}{|l|}{ Supervision by primary caretaker } \\
\hline Adequate & 9331 & 93.4 & 659 & 6.6 & $<0.001$ \\
\hline Inadequate & 1270 & 89.8 & 144 & 10.2 & \\
\hline \multicolumn{6}{|l|}{ Age of primary caretaker } \\
\hline$<20$ years & 713 & 90.0 & 79 & 10.0 & 0.002 \\
\hline 20-29 years & 5738 & 92.8 & 443 & 7.2 & \\
\hline 30-39 years & 3165 & 93.9 & 204 & 6.1 & \\
\hline$\geq 40$ years & 985 & 92.7 & 77 & 7.3 & \\
\hline \multicolumn{6}{|l|}{ Educational attainment of primary caretaker } \\
\hline No formal education/early childhood education & 2354 & 91.4 & 221 & 8.6 & 0.003 \\
\hline Primary & 4148 & 93.4 & 291 & 6.6 & \\
\hline Lower secondary or above & 4099 & 93.4 & 291 & 6.6 & \\
\hline \multicolumn{6}{|l|}{ Number of household members } \\
\hline$\leq 6$ people & 6712 & 93.4 & 473 & 6.6 & 0.014 \\
\hline$>6$ people & 3889 & 92.2 & 330 & 7.8 & \\
\hline \multicolumn{6}{|l|}{ Hand-washing facilities } \\
\hline Yes & 9577 & 92.9 & 729 & 7.1 & 0.756 \\
\hline No & 1024 & 93.3 & 74 & 6.7 & \\
\hline \multicolumn{6}{|l|}{ Water availability } \\
\hline Yes & 8838 & 93.1 & 651 & 6.9 & 0.096 \\
\hline No & 1763 & 92.1 & 152 & 7.9 & \\
\hline
\end{tabular}


Table 4. Cont.

\begin{tabular}{|c|c|c|c|c|c|}
\hline \multirow{2}{*}{ Characteristics } & \multicolumn{2}{|c|}{ No Diarrhea Episode } & \multicolumn{2}{|c|}{ Diarrhea Episode } & \multirow{2}{*}{$p$-Value ${ }^{1}$} \\
\hline & $n$ & $\%$ & $n$ & $\%$ & \\
\hline \multicolumn{6}{|l|}{ Soap availability } \\
\hline Yes & 5109 & 94.1 & 323 & 5.9 & $<0.001$ \\
\hline No & 5492 & 92.0 & 480 & 8.0 & \\
\hline \multicolumn{6}{|c|}{ Hand-washing facilities with water and soap ${ }^{3}$} \\
\hline Facility $(+)$, water $(+)$, soap $(+)$ & 5068 & 94.1 & 319 & 5.9 & $<0.001$ \\
\hline Facility $(+)$, water $(+)$, soap $(-)$ & 3770 & 91.9 & 332 & 8.1 & \\
\hline Facility $(+)$, water $(-)$, soap $(+/-)$ & 739 & 90.5 & 78 & 9.5 & \\
\hline Facility $(-)$, water $(-)$, soap $(-)$ & 1024 & 93.3 & 74 & 6.7 & \\
\hline \multicolumn{6}{|l|}{ Sanitation facilities } \\
\hline Improved sanitation facilities & 7289 & 93.6 & 500 & 6.4 & $<0.001$ \\
\hline Unimproved sanitation facilities & 266 & 87.2 & 39 & 12.8 & \\
\hline No facilities & 3046 & 92.0 & 264 & 8.0 & \\
\hline \multicolumn{6}{|l|}{ Source of drinking water } \\
\hline Improved & 8619 & 93.2 & 624 & 6.8 & 0.013 \\
\hline Unimproved & 1982 & 91.7 & 179 & 8.3 & \\
\hline \multicolumn{6}{|l|}{ Ownership of domestic animals } \\
\hline Yes & 8754 & 92.9 & 669 & 7.1 & 0.629 \\
\hline No & 1847 & 93.2 & 134 & 6.8 & \\
\hline \multicolumn{6}{|l|}{ Household wealth } \\
\hline First (poorest) & 2689 & 91.5 & 250 & 8.5 & $<0.001$ \\
\hline Second & 2560 & 92.2 & 216 & 7.8 & \\
\hline Third & 2656 & 93.3 & 190 & 6.7 & \\
\hline Forth (richest) & 2696 & 94.8 & 147 & 5.2 & \\
\hline \multicolumn{6}{|l|}{ Area } \\
\hline Urban & 2856 & 93.6 & 195 & 6.4 & 0.107 \\
\hline Rural & 7745 & 92.7 & 608 & 7.3 & \\
\hline \multicolumn{6}{|l|}{ Source water quality } \\
\hline$<11$ CFUs in all three samples & 1439 & 93.6 & 98 & 6.4 & 0.094 \\
\hline$\geq 11$ CFUs in one or two samples & 5084 & 92.4 & 417 & 7.6 & \\
\hline$\geq 11$ CFUs in all three samples & 4078 & 93.4 & 288 & 6.6 & \\
\hline
\end{tabular}

${ }^{1}$ Fisher's exact test. ${ }^{2}$ Chi-square test. ${ }^{3}(+)$ indicates presence, whereas (-) indicates absence.

\subsection{Multivariate Analyses}

In Model 1, the children whose households possess hand-washing facilities with water alone were significantly more likely to have a diarrhea episode compared to the reference group (i.e., the children whose households possess hand-washing facilities with both water and soap) (Table 5). This difference remained significant even after adjusting for the other predictor variables in Models 2 and 3. Children whose households possess handwashing facilities without water and with/without soap were significantly more likely to have a diarrhea episode compared to the reference group in Models 1 and 2. However, the association became insignificant in Model 3. There were no significant differences in the odds ratio of diarrhea episodes between children whose households do not possess hand-washing facilities and the reference group.

Additionally, in Model 3 there was a significant difference between the reference group and comparison group in the following characteristics; sex of child, age of child, supervision by primary caretaker, sanitation facilities, and household wealth. 
Table 5. Multivariate analysis of the association between diarrhea episodes among children under five and hand-washing facilities $(n=11404)$.

\begin{tabular}{|c|c|c|c|c|c|c|}
\hline \multirow{2}{*}{ Characteristics } & \multicolumn{2}{|c|}{ Model 1} & \multicolumn{2}{|c|}{ Model 2} & \multicolumn{2}{|c|}{ Model 3} \\
\hline & OR & $95 \%$ CI & AOR & $95 \%$ CI & AOR & $95 \% \mathrm{CI}$ \\
\hline \multicolumn{7}{|l|}{ Sex of child } \\
\hline Male & & & & & 1.00 & Reference \\
\hline Female & & & & & 0.82 & $0.69-0.98$ \\
\hline \multicolumn{7}{|l|}{ Age of child } \\
\hline 0 year & & & & & 1.00 & Reference \\
\hline 1 year & & & & & 1.14 & $0.90-1.46$ \\
\hline 2 years & & & & & 0.63 & $0.49-0.82$ \\
\hline 3 years & & & & & 0.41 & $0.31-0.54$ \\
\hline 4 years & & & & & 0.40 & $0.30-0.54$ \\
\hline \multicolumn{7}{|l|}{ Supervision by primary caretaker } \\
\hline Adequate & & & & & 1.00 & Reference \\
\hline Inadequate & & & & & 1.72 & $1.35-2.20$ \\
\hline \multicolumn{7}{|l|}{ Age of primary caretakere } \\
\hline$<20$ years & & & & & 1.00 & Reference \\
\hline 20-29 years & & & & & 0.88 & $0.64-1.22$ \\
\hline 30-39 years & & & & & 0.78 & $0.55-1.11$ \\
\hline$\geq 40$ years & & & & & 1.15 & $0.75-1.77$ \\
\hline \multicolumn{7}{|l|}{ Educational attainment of primary caretaker } \\
\hline No formal education/early childhood education & & & & & 1.00 & Reference \\
\hline Primary & & & & & 0.82 & $0.64-1.04$ \\
\hline Lower secondary or above & & & & & 0.97 & $0.73-1.29$ \\
\hline \multicolumn{7}{|l|}{ Number of household members } \\
\hline$\leq 6$ people & & & 1.00 & Reference & 1.00 & Reference \\
\hline$>6$ people & & & 1.17 & $0.97-1.40$ & 1.12 & $0.92-1.35$ \\
\hline \multicolumn{7}{|l|}{ Hand-washing facilities with water and soap ${ }^{1}$} \\
\hline Facility $(+)$, water $(+), \operatorname{soap}(+)$ & 1.00 & Reference & 1.00 & Reference & 1.00 & Reference \\
\hline Facility $(+)$, water $(+)$, soap $(-)$ & 1.49 & $1.22-1.81$ & 1.28 & $1.03-1.58$ & 1.31 & $1.05-1.63$ \\
\hline Facility $(+)$, water $(-), \operatorname{soap}(+/-)$ & 1.71 & $1.22-2.39$ & 1.50 & $1.07-2.12$ & 1.41 & $0.99-2.02$ \\
\hline Facility $(-)$, water $(-)$, soap $(-)$ & 1.18 & $0.86-1.63$ & 1.05 & $0.76-1.46$ & 1.03 & $0.74-1.45$ \\
\hline \multicolumn{7}{|l|}{ Sanitation facilities } \\
\hline Improved sanitation facilities & & & 1.00 & Reference & 1.00 & Reference \\
\hline Unimproved sanitation facilities & & & 2.14 & $1.35-3.37$ & 2.07 & $1.29-3.32$ \\
\hline No facilities & & & 0.99 & $0.78-1.25$ & 1.01 & $0.79-1.29$ \\
\hline \multicolumn{7}{|l|}{ Source of drinking water } \\
\hline Improved & & & 1.00 & Reference & 1.00 & Reference \\
\hline Unimproved & & & 1.11 & $0.88-1.41$ & 1.13 & $0.89-1.45$ \\
\hline \multicolumn{7}{|l|}{ Ownership of domestic animals } \\
\hline Yes & & & 1.00 & Reference & 1.00 & Reference \\
\hline No & & & 1.03 & $0.81-1.30$ & 1.02 & $0.80-1.30$ \\
\hline \multicolumn{7}{|l|}{ Household wealth } \\
\hline First (poorest) & & & 1.00 & Reference & 1.00 & Reference \\
\hline Second & & & 0.92 & $0.72-1.17$ & 0.90 & $0.70-1.16$ \\
\hline Third & & & 0.82 & $0.62-1.09$ & 0.80 & $0.59-1.08$ \\
\hline Forth (richest) & & & 0.66 & $0.48-0.91$ & 0.62 & $0.43-0.88$ \\
\hline \multicolumn{7}{|l|}{ Area } \\
\hline Urban & & & & & 1.00 & Reference \\
\hline Rural & & & & & 0.90 & $0.69-1.18$ \\
\hline \multicolumn{7}{|l|}{ Source water quality } \\
\hline$<11$ CFUs in the all the samples & & & & & 1.00 & Reference \\
\hline$\geq 11$ CFUs in one or two samples & & & & & 1.22 & $0.88-1.68$ \\
\hline$\geq 11$ CFUs in all the samples & & & & & 0.99 & $0.70-1.38$ \\
\hline Log likelihood & & -2846.48 & & -2834.31 & & -2767.01 \\
\hline Likelihood ratio test ( $p$-value) & & 0.0002 & & 0.0020 & & $<0.0001$ \\
\hline
\end{tabular}

${ }^{1}(+)$ indicates the presence, whereas $(-)$ indicates the absence. OR, odds ratio; CI, confidence interval; AOR, adjusted odds ratio. 


\section{Discussion}

The main finding of the present study was that children whose households possess hand-washing facilities with both water and soap were significantly less likely to experience diarrhea episodes compared to children whose households possess hand-washing facilities with water alone. This finding suggests that in the Lao setting, hand-washing with soap is more effective for preventing childhood diarrhea episodes compared to hand-washing without soap. This finding is important because hand-washing facilities with water are available in most households in Lao PDR. If soap use becomes more common, the mortality and morbidity due to diarrhea could be widely reduced.

This main finding is biologically plausible. Analysis of the samples collected at Lao healthcare facilities showed that the major etiologic agents of acute childhood diarrhea are rotavirus, Escherichia coli, and Salmonella spp. [22], which are transmitted from person-toperson via contaminated hands in households. A community-based study involving 1159 households in rural Lao PDR showed that enteropathogen infections are strongly correlated within members of the same household, suggesting the importance of intra-household transmission [14]. A randomized controlled trial with volunteers in the U.K. showed that hand-washing with plain soap is more effective for the removal of bacterial pathogens from hands than hand-washing with water alone [23]. A community-based randomized control trial with mothers in Bangladesh also showed that hand-washing with a bar of soap is more effective for reducing the bacterial load of coliforms and Clostridium perfringens compared to hand-washing with water alone [24]. Additionally, an experimental study with volunteers in the U.S. showed that hand-washing with hand soap and water is effective for reducing viral contamination from finger pads [25].

The main finding is also consistent with those reported from similar observational studies. A cross-sectional study involving 347 households in rural Bangladesh showed that children U5 whose family members washed their hands with soap after defecation were significantly less likely to experience a diarrhea episode in the $48 \mathrm{~h}$ preceding the survey compared to children whose family members washed their hands with water only [26]. A cross-sectional study in Malawi, which used Demographic and Health Survey data, showed that the lack of soap in hand-washing facilities was associated with higher odds of having a diarrhea episode among children U5 [27]. In contrast, the main finding of the present study is not consistent with the findings of a study conducted in Saravan province of the Lao PDR. There are two possible reasons for this inconsistency: first, the Saravan study used all household member's diarrhea episodes as the outcome, suggesting that the reason for the discrepancy could be due to methodological differences. Second, the Saravan study included only 46 diarrhea cases as the outcome, suggesting that the study likely suffered from type II errors; i.e., false negatives.

Although the effect of soap being present in hand-washing facilities on diarrhea incidence was not large (i.e., $5.9 \%$ among children in households with soap vs. $8.1 \%$ among children in households without soap), placing soap in hand-washing facilities could widely impact the health of Lao children, as more than one-third of Lao households do not have soap in their hand-washing facilities. Based on the assumption that a household has one child U5, 283,000 out of the total 786,000 children U5 in Lao could benefit from placing soap in hand-washing facilities. Additionally, the use of soap could contribute to preventing not only diarrhea, but also other illnesses including pneumonia, which is also a leading cause of death among Lao children [6,28].

The reasons for the absence of soap in hand-washing facilities in many households remain poorly understood in Lao PDR, as no study has been conducted in the country to explore these reasons. The LSIS II report showed, however, that there are some household trends for the absence of soap in handwashing facilities: rural households, households whose heads have lower educational attainment, households of lower wealth quintiles, and households of minority language groups are less likely to have soap in their handwashing facilities compared to their counterparts [4]. A study on hand-washing facilities in 51 countries reported similar trends: universally, households of higher wealth quintiles and 
urban households are more likely to have soap in their hand-washing facilities, compared to their counterparts [29]. In Lao PDR, however, soap seems to be affordable for many people: the average price of a bar of soap was 3110 kip (approximately 0.34 U.S. dollars) in 2017 [30]. Considering these trends and the price of soap, further study is necessary to identify the barriers to placing soap in hand-washing facilities in Lao PDR.

The results of the present study also showed that there was no significant difference in the incidence of diarrhea between households with hand-washing facilities where soap and water are available and households without hand-washing facilities. A possible explanation for the lack of a difference is that the households without hand-washing facilities include a substantial proportion of households that live near a community well, and thus household members use the community well as a hand-washing facility. A community-shared well is commonly seen in rural villages of Lao PDR. In fact, wells are a major source of water for housework, including hand-washing, in rural Lao PDR [4]. Additionally, according to the LSIS II survey, in the $66.7 \%$ of households their toilet facilities were located not in their houses but in their yards. Thus, there is a possibility that household members have little difficulty in using a community well after defecation, if they live near a community well.

Likewise, in the present study there was no significant difference in the incidence of diarrhea between households with improved sanitation facility and households with no sanitation facility. Currently, we are unable to provide a possible reason for the lack of a difference. A multi-country case control study, which assessed sanitation and hygienespecific risk factors for moderate-to-severe childhood diarrhea, also showed that there was no significant difference in the risk of diarrhea between households with private sanitation facilities and households with no sanitation facility in, for example, Bangladesh [31]. However, the case-control study did not provide any possible reasons.

A major limitation of the present study is the absence of information about actual hand-washing practices. It is of concern whether the study participants of the households where soap is available in hand-washing facilities actually use soap, as studies have shown that in settings where soap is available, people do not necessarily use soap when washing their hands before/after critical events such as fecal contact, food preparation, eating, and feeding a child. A school-based study in Lao PDR observed that of the pupils who used the school toilet, only $23.9 \%$ washed their hands with soap afterward [12]. A multicountry study that evaluated the validity of rapid observation measures of hand-washing practices concluded that the observation of hand-washing materials in hand-washing facilities is a valid measure of hand-washing with soap, although the use of soap is often suboptimal: $27-82 \%$ of the primary caretakers of children U5 used soap after possible fecal contact, and overall, they used soap before $24-36 \%$ of critical events [32].

Another limitation is that the present study was not able to incorporate all the factors which are reported to be associated with childhood diarrhea episodes in similar studies. Such factors include food preparation practices and child feces disposal practices. For example, a cross-sectional study in Viet Nam showed that the risk of childhood diarrhea was significantly higher among children whose mothers prepared food for cooking somewhere other than the table, compared to children whose mothers prepared food on the table [33]. A cross-sectional study using the data of the 2013 Nigerian Demographic and Health Survey reported that the increased risk of childhood diarrhea was significantly associated with unsafe child feces disposal practices of caretakers [16].

In order to maximize the effect of hand-washing on preventing communicable diseases, merely recommending hand-washing with soap before/after critical events is not enough. The Centers for Disease Control and Prevention recommends the five steps for domestic hand-washing: wetting hands with clean, running water; lathering hands by rubbing hands together with soap; scrubbing hands for at least $20 \mathrm{~s}$; rinsing hands well under clean, running water; and drying hands using a clean towel or air dry hands [34]. A communitybased study with primary caregivers of school children in Zimbabwe demonstrated the importance of these five steps in removing microbial contamination [35]. A health education intervention study in Hong Kong showed that the five-steps hand hygiene tech- 
nique was effective in reducing the spread of infectious diseases in the special education school setting [36]. Because children learn hand-washing from their primary caretakers whose hand hygiene practices are sometimes suboptimal [37,38], health education interventions on hand hygiene to children and caretakers are recommended to promote effective hand-washing.

The results of the present study showed that most of the households with children U5 already had improved sanitation facilities $(70.2 \%)$ and improved source of drinking water $(82.2 \%)$, whereas only $49.1 \%$ of the households with children U5 had hand-washing facilities with water and soap. The results suggest that hygiene education does not keep up with the increased coverage of sanitation and water supply. Therefore, more efforts should be made in promoting hygiene education in Lao PDR. The proportion of the population that use hand-washing facilities with water and soap is one of the indicators for Target 6.2 of Sustainable Development Goal 6: "By 2030, achieve access to adequate and equitable sanitation and hygiene for all and end open defecation, paying special attention to the needs of women and girls and those in vulnerable situations" [39]. The present study showed that the proportion of households using hand-washing facilities with water and soap is $49.1 \%$, suggesting that continued efforts are needed to achieve Target 6.2 in Lao PDR. In 2017, globally, $60 \%$ of the population had basic hand-washing facilities with water and soap, whereas $22 \%$ had limited hand-washing facilities lacking water and/or soap [40]. Therefore, many countries, including Lao PDR, face the same challenge: trying to increase the population using basic hand-washing facilities with water and soap.

\section{Conclusions}

The absence of soap in hand-washing facilities was associated with higher odds of having a diarrhea episode among children under five years of age. This suggests that hand-washing with soap is effective for preventing childhood diarrhea in Lao household settings. Households can reduce the risk of diarrhea among their children by making soap available in hand-washing facilities. Further study is necessary to inform strategies for increasing the availability of soap in hand-washing facilities in every household of Lao PDR.

Supplementary Materials: The following are available online at https://www.mdpi.com/1660-460 1/18/2/687/s1, Spreadsheet S1: Dataset.

Author Contributions: Conceptualization, Y.N. and D.N.; methodology, Y.N. and D.N.; formal analysis, Y.N.; writing—original draft preparation, Y.N.; writing—review and editing, D.N.; supervision, S.K. and J.K.; project administration, D.N.; funding acquisition, D.N. All authors have read and agreed to the published version of the manuscript.

Funding: This work is supported by JSPS KAKENHI Grant Number JP19K10665.

Institutional Review Board Statement: Not applicable.

Informed Consent Statement: Not applicable.

Data Availability Statement: The data are available at the Supplementary Materials.

Acknowledgments: The authors sincerely thank the participants of the LSIS II for their cooperation with this survey.

Conflicts of Interest: The authors declare no conflict of interest. 


\section{Appendix A}

Table A1. Detailed explanation of the predictor variables.

\begin{tabular}{|c|c|}
\hline Variables & Category Details \\
\hline Supervision by primary caretaker & $\begin{array}{l}\text { This variable has two categories: "adequate" and "inadequate." This variable is an original variable of the LSIS II, } \\
\text { where the primary caretaker's response to the following two questions determined the category: (1) "On how many } \\
\text { days in the past week was (child name) left alone for more than an hour?" and (2) "On how many days in the past } \\
\text { week was (child name) left in the care of another child that was less than } 10 \text { years old for more than an hour?" When } \\
\text { the primary caretaker's response to questions } 1 \text { and/or } 2 \text { were one day or more, the supervision was defined as } \\
\text { "inadequate" in the LSIS II. Otherwise, the supervision was defined as "adequate." }\end{array}$ \\
\hline Educational attainment of primary caretaker & $\begin{array}{l}\text { In the LSIS II, the educational attainment of the primary caretakers was divided the following six categories: } \\
\text { "none/early childhood education," "primary," "lower secondary," "upper secondary," } \\
\text { "post-secondary/non-tertiary," and "higher." In the present study, "lower secondary," "upper secondary," } \\
\text { "post-secondary/non-tertiary," and "higher" were combined into one category, titled "lower secondary or above," } \\
\text { because "upper secondary," "post-secondary/non-tertiary," and "higher" accounted for a small proportion of less } \\
\text { than } 8 \% \text { for each. Therefore, the educational attainment in the present study could be divided into the following } \\
\text { three categories: "no formal education or early childhood education," "primary," and "lower secondary or above." }\end{array}$ \\
\hline Number of household members & $\begin{array}{l}\text { In the LSIS II, the number of household members was surveyed in a continuous manner. In the present study, } \\
\text { the number of household members was dichotomized using the median, i.e., six. Therefore, this variable has two } \\
\text { categories: "six or fewer" and "over six." }\end{array}$ \\
\hline Sanitation facilities & $\begin{array}{l}\text { This variable has three categories: "improved sanitation facilities," "unimproved sanitation facilities," and "no } \\
\text { facilities." This variable is an original variable of the LSIS II, where the respondent's response to the following } \\
\text { question determined the category: "What kind of toilet facilities do members of your household usually use?" In the } \\
\text { LSIS II, "improved sanitation facilities" included flush/pour-flush (to a piped sewer system/septic tank/pit latrine), } \\
\text { ventilated improved pit latrine, pit latrine with slab, and composting toilet. "Unimproved sanitation facilities" } \\
\text { included flush/pour-flush to an open drain, pit latrine without slab or open pit, hanging toilet, and hanging latrine. }\end{array}$ \\
\hline
\end{tabular}

included flush/pour-flush to an open drain, pit latrine without slab or open pit, hanging toilet, and hanging latrine.

Source of drinking water where the respondent's response to the following question determined the category: "What is the main source of drinking water used by members of your household?" In the LSIS II, "improved" included piped water, tube well/borehole, protected dug well, protected spring, rainwater collection, and packaged/delivered water. "Unimproved" included unprotected well/spring and surface water.

Ownership of domestic animals

This variable has two categories: "yes" and "no." This variable is an original variable of the LSIS II, where the respondent's response to the following question determined the category: “Does this household own any livestock, herds, other farm animals, or poultry?"

This variable was measured by an asset-based wealth index [21]. The household assets included in the present study were: television, refrigerator, fan, water pump, air conditioner, washing machine, CD/DVD player/home theatre, iron, rice cooker/steam cooker, watch, bicycle, motorcycle/scooter, animal-drawn cart, car/truck/van, boat with a motor, and Tak Tak (two-wheeled tractor with trailer). Principal component analysis was used to assess the weight of these household assets and to build an asset index by which households were divided into quartiles. The first component was used for the asset index, which explained $30.9 \%$ of the total variance. The scoring factor of the asset was 0.301 for television, 0.357 for refrigerator, 0.334 for fan, 0.225 for water pump, 0.206 for air conditioner, 0.313 for washing machine, 0.191 for CD/DVD player/home theatre, 0.327 for iron, 0.347 for rice cooker/steam cooker, 0.246 for watch, 0.211 for bicycle, 0.196 for motorcycle/scooter, 0.005 for animal-drawn cart, 0.258 for car/truck/van 0.044 for boat with a motor, and 0.060 for Tak Tak.

In the LSIS II, area was divided into three categories: "urban," "rural with road," and "rural without road." In the present study, "rural with road" and "rural without road" were combined into one category, titled "rural," according to similar studies [27]. In the LSIS II, the definition of urban/rural followed the Lao Statistics Bureau's village register in 2015: a village was classified as urban if it met at least three out of the following five conditions: (a) the village is situated in a district or provincial center, (b) more than $70 \%$ of the total households in the village use electricity, (c) more than $70 \%$ of the total households in the village use piped water, (d) the village is accessible by road throughout year, and (e) the village has a permanent market that is operating daily [41].

This variable is a new aggregate variable that represents the quality of the village's source water. The variable was developed for the present study on the basis of the data of household-based water quality testing. In the LSIS II, water quality testing was conducted at three randomly selected households per village, and the colony-forming units (CFUs) of Escherichia coli per $100 \mathrm{~mL}$ were counted for each household-based sample. In the present study, the CFUs were dichotomized using a cut-off value of 11, according to a study in Cambodia which reported that diarrhea disease is significantly associated with 11 or more CFUs of E. coli/100 mL of drinking water [42]. When the test result was $<11$ CFUs in all three samples, the quality of the village's source water was considered to be of low risk for causing diarrhea. When the test result was $\geq 11$ CFUs in one or two samples, the quality of the village's source water was considered to be of moderate risk. When the test result was $\geq 11 \mathrm{CFU}$ in all three samples, the quality of the village's source water was considered to be of high risk. Therefore, this variable has the following three categories: $<11$ CFU in all three samples, $\geq 11$ CFU in one or two samples, and $\geq 11$ CFU in all three samples.

\section{References}

1. United Nations Interagency Group for Child Mortality Estimation (UNIGME). Levels \& Trends in Child Mortality Report 2019 Estimates Developed by the United Nations Interagency Group for Child Mortality Estimation. Available online: https: / / data.unicef.org/wp-content/uploads/2019/09/UN-IGME-Child-Mortality-Report-2019-1.pdf (accessed on 14 January 2021).

2. World Health Statistics. Monitoring Health for the SDGs, Sustainable Development Goals. Available online: https: / apps.who. int/iris/bitstream/handle/10665/272596/9789241565585-eng.pdf?ua=1 (accessed on 14 January 2021).

3. World Health Organization. Diarrhoeal Disease. Available online: https://www.who.int/news-room/fact-sheets/detail/ diarrhoeal-disease (accessed on 14 January 2021). 
4. Lao Statistics Bureau. Lao Social Indicator Survey II (LSIS II). Available online: https:/ /lao.unfpa.org/sites/default/files/pubpdf/Lao\%20Social\%20Inndicator\%20Survey\%20II\%202017-18\%20\%28English\%29_0.pdf (accessed on 14 January 2021).

5. United Nations Children's Fund Data. Under-Five Mortality. Available online: https://data.unicef.org/topic/child-survival/ under-five-mortality / (accessed on 14 January 2021).

6. Unicef for Every Child Lao People's Democratic Republic. Health Ensuring the Survival and Health of Children and Women. Available online: https:/ / www.unicef.org/laos/health (accessed on 14 January 2021).

7. GBD 2016 Diarrhoeal Disease Collaborators. Estimates of global, regional, and national morbidity, mortality, and aetiologies of diarrhoeal diseases: A systematic analysis for the Global Burden of Disease Study 2015. Lancet Infect Dis. 2017, 17, 909-948. [CrossRef]

8. Curtis, V.; Cairncross, S. Effect of washing hands with soap on diarrhoea risk in the community: A systematic review. Lancet Infect Dis. 2003, 3, 275-281. [CrossRef]

9. Ejemot-Nwadiaro, R.I.; Ehiri, J.E.; Arikpo, D.; Meremikwu, M.M.; Critchley, J.A. Hand washing promotion for preventing diarrhoea. Cochrane Database Syst. Rev. 2015, 3, CD004265. [CrossRef] [PubMed]

10. Pavani Ram. Practical Guidance for Measuring Handwashing Behavior: 2013 Update. Available online: https://www.wsp. org/sites/wsp/files / publications /WSP-Practical-Guidance-Measuring-Handwashing-Behavior-2013-Update.pdf (accessed on 14 January 2021).

11. United Nations Lao PDR. 8th National Socio-Economic Development Plan (2016-2020). Available online: https:/ /laopdr.un.org/ sites/default/files/2019-08/2016_8th\%20NSEDP_2016-2020_English.pdf (accessed on 14 January 2021).

12. Chard, A.N.; Freeman, M.C. Design, Intervention Fidelity, and Behavioral Outcomes of a School-Based Water, Sanitation, and Hygiene Cluster-Randomized Trial in Laos. Int. J. Environ. Res. Public Health 2018, 15. [CrossRef]

13. Chard, A.N.; Garn, J.V.; Chang, H.H.; Clasen, T.; Freeman, M.C. Impact of a school-based water, sanitation, and hygiene intervention on school absence, diarrhea, respiratory infection, and soil-transmitted helminths: Results from the WASH HELPS cluster-randomized trial. J. Glob. Health 2019, 9, 020402. [CrossRef]

14. Chard, A.N.; Levy, K.; Baker, K.K.; Tsai, K.; Chang, H.H.; Thongpaseuth, V.; Sistrunk, J.R.; Freeman, M.C. Environmental and spatial determinants of enteric pathogen infection in rural Lao People's Democratic Republic: A cross-sectional study. PLoS Negl. Trop. Dis. 2020, 14. [CrossRef]

15. Vannavong, N.; Overgaard, H.J.; Stenström, T.A.; Seidu, R. Assessing the Risk Factors of Diarrhoeal Disease in Suburban and Rural Villages in Laos and Thailand. Available online: https://nmbu.brage.unit.no/nmbu-xmlui/bitstream/handle/11250/2500 628/2017-89_Nanthasane\%20Vannavong_\%28IMT\%29.pdf?sequence=4\&isAllowed=y (accessed on 14 January 2021).

16. Berde, A.S.; Yalcin, S.S.; Ozcebe, H.; Under, S.; Karadag-Caman, O. Determinants of childhood diarrhea among under-five year old children in Nigeria: A population-based study using the 2013 demographic and health survey data. Turk. J. Pediatr. 2018, 60, 353-360. [CrossRef]

17. To, K.G.; Lee, J.K.; Nam, Y.S.; Trinh, O.T.H.; Do, D.V. Hand washing behavior and associated factors in Vietnam based on the Multiple Indicator Cluster Survey, 2010-2011. Glob. Health Action 2016, 9, 101-107. [CrossRef]

18. Aziz, F.A.A.; Ahmad, N.A.; Razak, M.A.A.; Omar, M.; Kasim, N.M.; Yusof, M.; Sooryanarayana, R.; Jamaludin, R.; Ying, C.Y. Prevalence of and factors associated with diarrhoeal diseases among children under five in Malaysia: A cross-sectional study 2016. BMC Public Health 2018, 18. [CrossRef]

19. Kawakatsu, Y.; Tanaka, J.; Ogawa, K.; Ogendo, K.; Honda, S. Community unit performance: Factors associated with childhood diarrhea and appropriate treatment in Nyanza Province, Kenya. BMC Public Health 2017, 17. [CrossRef]

20. Siziya, S.; Muula, A.S.; Rudatsikira, E. Diarrhoea and acute respiratory infections prevalence and risk factors among under-five children in Iraq in 2000. Ital. J. Pediatr. 2009, 35. [CrossRef] [PubMed]

21. Vyas, S.; Kumaranayake, L. Constructing socio-economic status indices: How to use principal components analysis. Health Policy Plan 2006, 21, 459-468. [CrossRef] [PubMed]

22. Houattongkham, S.; Yamamoto, E.; Sithivong, N.; Inthaphatha, S.; Kariya, T.; Saw, Y.M.; Vongduangchanh, A.; Keosavanh, O.; Hamajima, N. Etiologic agents of acute diarrhea in sentinel surveillance sites in Vientiane Capital, Lao People's Democratic Republic, 2012-2015. Eur. J. Clin. Microbiol. Infect. Dis. 2020, 39, 1115-1122. [CrossRef] [PubMed]

23. Burton, M.; Cobb, E.; Donachie, P.; Judah, G.; Curtis, V.; Schmidt, W.-P. The Effect of Handwashing with Water or Soap on Bacterial Contamination of Hands. Int. J. Environ. Res. Public Health 2011, 8, 97-104. [CrossRef] [PubMed]

24. Amin, N.; Pickering, A.J.; Ram, P.K.; Unicomb, L.; Najnin, N.; Homaira, N.; Ashraf, S.; Abedin, J.; Islam, M.S.; Luby, S.P. Microbiological Evaluation of the Efficacy of Soapy Water to Clean Hands: A Randomized, Non-Inferiority Field Trial. Am. J. Trop. Med. Hyg. 2014, 91, 415-423. [CrossRef]

25. Tuladhar, E.; Hazeleger, W.C.; Koopmans, M.; Zwietering, M.H.; Duizer, E.; Beumer, R.R. Reducing viral contamination from finger pads: Handwashing is more effective than alcohol-based hand disinfectants. J. Hosp. Infect. 2015, 90, 226-234. [CrossRef] [PubMed]

26. Luby, S.P.; Halder, A.K.; Huda, T.; Unicomb, L.; Johnston, R.B. The Effect of Handwashing at Recommended Times with Water Alone and with Soap on Child Diarrhea in Rural Bangladesh: An Observational Study. PLoS Med. 2011, 8. [CrossRef]

27. Moon, J.; Choi, J.W.; Oh, J.; Kim, K.H. Risk factors of diarrhea of children under five in Malawi: Based on Malawi Demographic and Health Survey 2015-2016. J. Glob. Health Sci. 2019, 1. [CrossRef] 
28. Luby, S.P.; Agboatwalla, M.; Feikin, D.R.; Painter, J.; Billhimer, W.; Altaf, A.; Hoekstra, R.M. Effect of handwashing on child health: A randomised controlled trial. Lancet 2005, 366, 225-233. [CrossRef]

29. Kumar, S.; Loughnan, L.; Luyendijk, R.; Hernandez, O.; Weinger, M.; Arnold, F.; Ram, P.K. Handwashing in 51 Countries: Analysis of Proxy Measures of Handwashing Behavior in Multiple Indicator Cluster Surveys and Demographic and Health Surveys, 2010-2013. Am. J. Trop. Med. Hyg. 2017, 97, 447-459. [CrossRef]

30. Ministry of Planning and Investment Lao Statistics Bureau. Statistical Yearbook 2017. Available online: https://seadelt.net/ Asset/Source/Document_ID-291_No-01.pdf (accessed on 14 January 2021).

31. Baker, K.K.; O’Reilly, C.E.; Levine, M.M.; Kotloff, K.L.; Nataro, J.P.; Ayers, T.L.; Farag, T.H.; Nasrin, D.; Blackwelder, W.C.; Wu, Y.; et al. Sanitation and Hygiene-Specific Risk Factors for Moderate-to-Severe Diarrhea in Young Children in the Global Enteric Multicenter Study, 2007-2011: Case-Control Study. PLoS Med. 2016, 3, e1002010. [CrossRef] [PubMed]

32. Ram, P.K.; Sahli, M.W.; Arnold, B.; Colford, J.M.; Chase, C.; Briceño, B.; Orsola-Vidal, A.; Gertler, P. Global Scaling Up Handwahing Validity of Rapid Measures of Handwashing Behavior: An Analysis of Data from Multiple Impact Evaluations in the Global Scaling Up Handwashing Project. Available online: https:/ /www.wsp.org/sites/wsp/files/publications/WSP-Validity-RapidMeasurement-Handwashing-Behavior.pdf (accessed on 14 January 2021).

33. Takahashi, K.; Chonan, Y.; Quyen, D.T.; Khan, N.C.; Poudel, K.C.; Jimba, M. Survey of Food-hygiene Practices at Home and Childhood Diarrhoea in Hanoi, Viet Nam. J. Health Popul. Nutr. 2009, 27, 602-611. [CrossRef]

34. Centers for Disease Control and Prevention. Handwashing: Clean Hands Save Lives. Available online: https://www.cdc.gov/ handwashing/when-how-handwashing.html (accessed on 14 January 2021).

35. Friedrich, M.N.D.; Julian, T.R.; Kappler, A.; Nhiwatiwa, T.; Mosler, H.-J. Handwashing, but how? Microbial effectiveness of existing handwashing practices in high-density suburbs of Harare, Zimbabwe. Am. J. Infect. Control 2017, 1, 228-233. [CrossRef] [PubMed]

36. Lee, R.L.T.; Leung, C.; Tong, W.K.; Chen, H.; Lee, P.H. Comparative efficacy of a simplified handwashing program for improvement in hand hygiene and reduction of school absenteeism among children with intellectual disability. Am. J. Infect. Control 2015, 43, 907-912. [CrossRef] [PubMed]

37. Okyay, P.; Ertug, S.; Gultekin, B.; Onen, O.; Beser, E. Intestinal parasites prevalence and related factors in school children, a western city sample-Turkey. BMC Public Health 2004, 22, 64. [CrossRef]

38. Parveen, S.; Nasreen, S.; Allen, J.V.; Kamm, K.B.; Khan, S.; Akter, S.; Lopa, T.M.; Zaman, K.; Arifeen, E.S.; Luby, P.S.; et al. Barriers to and motivators of handwashing behavior among mothers of neonates in rural Bangladesh. BMC Public Health 2018, 11, 483. [CrossRef]

39. United Nations. Global Indicator Framework for the Sustainable Development Goals and Targets of the 2030 Agenda for Sustainable Development. Available online: https://unstats.un.org/sdgs/indicators/Global\%20Indicator\%20Framework\%20 after\%202020\%20review_Eng.pdf (accessed on 14 January 2021).

40. World Health Organization. Progress on Household Drinking Water, Sanitation and Hygiene 2000-2017. Special Focus on Inequalities. Available online: https:/ /www.who.int/water_sanitation_health/publications/jmp-report-2019/en/ (accessed on 14 January 2021).

41. Ministry of Planning and Investment Lao Statistics Bureau. Lao Population and Housing Census 2015 Provisional Report. Available online: https://lao.unfpa.org/sites/default/files/pub-pdf/Final\%20report-editting-English1.pdf (accessed on 14 January 2021).

42. Brown, J.M.; Proum, S.; Sobsey, M.D. Escherichia coli in household drinking water and diarrheal disease risk: Evidence from Cambodia. Water Sci. Technol. 2008, 58, 757-763. [CrossRef] 